Please note that all letters must be typed. Priority will be given to those that are less than $\mathbf{5 0 0}$ words long. All authors must sign the letter, which may be shortened or edited for reasons of space or clarity. All letters received are acknowledged.

\section{Women in dentistry}

Sir, - After 10 years of satisfying full-time service to NHS dentistry as I await the delivery of my first child in trepidation, I am cheered by C Lister's letter (BDJ 2000; 190; 58) to discover that, at last, the full meaning of my life is about to become clear.

So the egalitarian domestic bliss which I and those of my generation have enjoyed for so long (I work in practice while he does the cleaning and the supermarket shop; I make the nursery curtains, he unblocks the waste disposal unit before cooking Sunday lunch) is false after all and now I can look forward to homemaking without his interference and 'be the true power behind (my) ambitious and successful' husband. Odd that I had mistaken this role to be his, or rather to be mutual!

On a serious note, I accept that the balanced nature of our gender roles is about to change with the arrival of our baby, but this will be made more difficult by the fact that my husband works in the male dominated world (i.e. unenlightened) of the construction industry. I am envious of my male dental friends who can (and do) share childcare with their wives because they have the ability to block off their diaries or work on a sessional basis.

I am increasingly aware that dentists of my generation value the flexibility that a dental career provides, with both male and female dentists intending to combine hospital and practice careers on a full or part time basis so that they can enjoy more time to themselves, be it to care for a child, shop or to play golf.

So let's be truly politically correct and acknowledge that the really attractive aspect of dentistry is the opportunity for flexible working which exists to be enjoyed by men and women alike.

\section{Nightingale \\ Taunton}

\section{Special care dentistry}

Sir, - My impending retirement in 1996 and the consequent vacancy for the lead clinician for the Special Needs Unit at Guys Dental Hospital created a similiar problem to that outlined by M. Griffiths. ${ }^{1}$

The late Professor Ashley, and his advisors overcame the status problem by creating a new post of senior lecturer with the possibility of honorary consultant status.
This left open the specialty to the experience and training of the successful candidate. Back in 1994, a working group on specialty status of what is now known as the British Society for Disability and Oral Health, of which I was chair, examined the role of experienced clinicians providing special care dentistry. It immediately became apparent that they were providing a high level of holistic care for a challenging group of people.

To be able to care for patients from 3-100+ years of age, an extensive knowledge and skills in the other recognised dental specialities is required. In the eyes of some leaders (members) of the profession this wide range of knowledge and skill was regarded as generalisation not expertise, failing to appreciate that these 'special care experts' are providing care for the most severely disabled people. If it is so easy and lacking in special skill why do recognised specialists show such little enthusiasm for people with severe disabilities?

As 13 per cent of the UK population is registered as disabled there is a significant gap in the availability of specialist dental services, which should be seen in relation to the Disability Discrimination Act.

The profession is content to leave care of people with special needs to the enthusiasts and, as Griffiths points out, fails to support these clinicians by recognising their hard won expertise with specialty status. Slow progress is being made and is reported in a recent publication. ${ }^{2}$ Is it too much to hope that specialty of 'special care dentistry' will be established by $2004-10$ years after the first moves?

\section{P. Erridge}

\section{East Grinstead}

1 Griffiths M. Special needs dentistry. Br Dent J 2000; 189: 470

2 Woof M. Specialisation in Special Care Dentistry - where from, where now, where to? J. Disab and Oral Health 2000; 34-35

\section{Fracture causes cyst}

Sir, - I wish to describe an interesting case of an ameloblastic fibroma associated with an unerupted tooth in a healed mandibular fracture. Ameloblastic fibroma is a rare benign tumour representing two per cent of all odontogenic tumours (see Fig. 1) and a review of the literature does not suggest a possible role for trauma as an aetiological factor.

An eight-year-old girl presented to the A\&E department following a road traffic accident in which she sustained a fracture to her right mandible. Radiographic examination showed a displaced fracture of the right body of the mandible involving the developing LR7 (Fig. 1). The fracture was reduced under general anaesthesia using silver cap splints.

The patient then attended for a review some 10 months post-operatively. An OPT was taken (Fig. 2) which showed the presence of a unilocular radiolucency associated with the LR7 which had been displaced towards the lower border. Clinically there was expansion of the buccal cortical plate, normal sensation of the lower lip and no associated lymphadenopathy.

The girl was admitted for enucleation of the cyst and extraction of the LR7. At operation a cystic lesion was found attached to the amelocemental junction in the manner of a follicular cyst. Histological examination of the specimen diagnosed an ameloblastic fibroma.

This is the first reported case of an ameloblastic fibroma occurring in the line of a healed mandibular fracture involving a developing tooth germ.

It raises the possibility of an association between disruption of a tooth germ, in this

Fig. I A PA skull showing the mandibular fracture involving the LR7. Fig. 2 (bottom) An OPT showing the LR7 and associated ameloblastic fibroma)

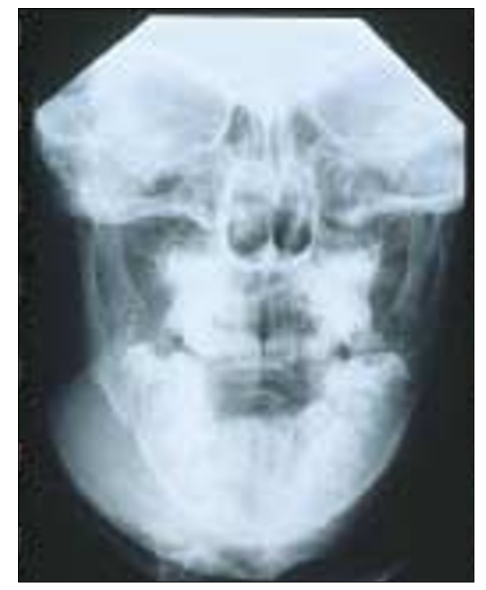

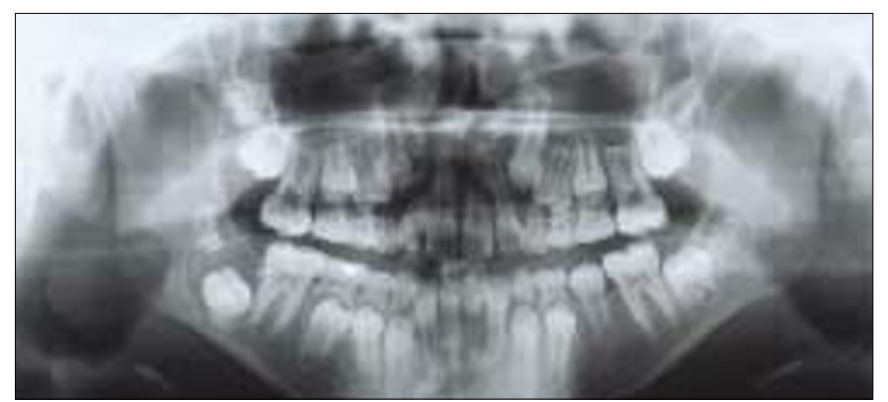


case by a fracture, and the development of an ameloblastic fibroma.

It is therefore recommended that fractures involving tooth germs are followed up not only to ensure proper tooth development but also to exclude the possibility of developing pathology.

\section{P. Williams}

Taunton

1 Soumes J V, J C, Oral Path 1996, 2nd Edition: 263-268, Oxford Medical Publications

\section{Prosthetic parts}

Sir, - I would like to congratulate the authors of the recent excellent series of prosthetic articles: despite the first class conservative work of most of my younger colleagues a minority of patients will require some type of denture.

May I venture to suggest the ubiquitous $0.75 \mathrm{~mm}$ hard drawn stainless steel wire remains an excellent material for the construction of clasps. I have found that if the wire is suitably tapered good molar and premolar clasps may be constructed by taking the mesial branch of the clasp one side of the survey line then bending the wire back up on itself and continuing the distal part of the retainer the other side of the line.

Tapered stainless steel wire can easily be made by taking a short length of wire (about $60 \mathrm{~mm}$ ) connecting one end to the anode lead of a chrome cobalt electrolytic polishing bath and moving the other end vertically and repeatedly into and out of the bath. In a few minutes sufficient metal is removed from the wire in a 'first in last out' principle to produce a useful taper.

\section{J. M. Buddery}

\section{Gorleston}

\section{Prescribing patients out of hours}

Sir, - I have recently encountered similar difficulty to Dr S Orlans (BDL 2000; 186 : 602 ) in prescribing for a patient in out-ofoffice hours. After many years of satisfactory interaction with a variety of pharmacists by telephone first and then by sending the appropriate paperwork on the next working day I have been told that his facility is no longer available.

It is iniquitous that professional duty of care and patient expectation are placed under such a burden by a Medicines Act (1968) that is 32 years out of date. Are my representatives at the BDA addressing this matter with the relevant authorities?

Surely it is not unusual in these days of personal service orientated dentistry for patients to travel considerable distances to attend the dentist of their choice.
This very weekend a patient had to undertake an 80 mile round trip across Kent and Sussex to collect from the supply of antibiotics I delibrately carry with me when away from the office.

Naturally, my first concern is to deal with the problem (invariably infection) in a proper clinical manner but this is not always appropriate or convenient for both parties. When approached, my patient's GMP did not have an appointment free for several days and, when the need for an appointment was explained, the response given was 'this is dental so you need to see your dentist'. What a beautiful example of Catch 22 ?

We seem to have achieved the courtesy title 'doctor' some 30 years into my career. Perhaps we could use the literal meaning of the title - teacher - to illuminate the thinking in the corridors of power since I should like the freedom to comply with my duty and the privilege to prescribe throughout the entire week to be returned to me before I retire.

\section{P. J. Newman Brown Kent}

\section{Time for treatment}

Sir, - I have not found that there is bemusement among patients about the cost of paying for extra time to do the same treatments as in the NHS (BDJ2000; 190:57)

Actually it is the time issue which underlies most of the reasons given by patients for joining our private practice (eg. the checkups are too rushed; the same filling keeps coming out; the pain hasn't really gone; s/he didn't seem to take me seriously).

There is now an unease in the wider NHS that GPs do not have enough time to diagnose properly, the ward nurses are too busy and shortstaffed, the consultants are overloaded and that this leads to more mistakes, more misunderstandings and a sense of being treated with disrespect.

If their GP does not diagnose right first time, NHS medical patients can return any number of times without cost. This is not true for NHS dental patients and paying (albeit small amounts) several times builds this feeling of disrespect. The sad thing is that not having enough time to do the work well builds this feeling of being disrespected in the dentist also. It can be a lose-lose situation and can lower morale.

I fear no amount of quality initiatives, clinical audit or governance will succeed unless this time issue is addressed in all sectors of the NHS. It can only be the hospital accountants that appreciated the late Rodney Ledward as 'the fastest gynaecologist in the west'.

\section{J. E. Fenwick \\ Newport}

\section{Seeking families with missing teeth}

Sir, - Do you know of individuals with missing teeth? Does this condition run in their family?

We welcome referrals to such individuals for a study relating to the identification of genes that cause such inherited conditions. Our long term goal is to evaluate factors important for tooth development in humans and to determine how mutations within genes encoding these factors contribute to the expression of the gene in the individual's development. Please do contact us with information about any patients you know of that fit these parameters, we would appreciate your collaboration. Cases that are selected as part of the study would qualify you as a co-author of the published paper.

Requirements for participation in the study are as follows:

Individuals must be healthy (i.e. without a diagnosed medical syndrome such as ectodermal dysplasia)

Study focuses on individuals with congenitally missing teeth and these teeth should preferably be those other than wisdom teeth. However, if the individual has numerous missing teeth and these include wisdom teeth, they would be valuable to our study.

Other family members must be similarly affected, although the actual pattern of missing teeth can vary from person to person in the family. We prefer families with five or more members affected.

Some individuals never shed their 'primary' (baby) teeth and there is typically no sign of permanent teeth when an $\mathrm{x}$-ray is taken. Such individuals would also qualify for our study.

This exciting study builds on the landmark research work already published by one of us ${ }^{1}$ on the identification of a gene underlying missing molar teeth. Your help in locating these patients with congenitally missing teeth is essential and much appreciated. Any questions you might have can be answered quickly by either of us.

The contact investigators are: Pragna I. Patel, Principal Investigator, Baylor College of Medicine, One Baylor Plaza, NB-302, Houston, TX 77030. Tel: 713/798-5823. Fax: 713/798-8526.email: pragna@bcm.tmc.edu

Or contact Donald T. Brown, Co-Investigator, Orthodontist-Private Practice, 5001 Highway 190, Suite A-6, Covington, LA 70433. Tel: 504-893-9425. Fax: 504-8930489. email: tmjdrdth@aol.com

\section{P. I. Patel}

\section{Houston, TX}

1 Stockton, D. et al. Mutation of $P A X 9$ associated with oligodontia. Nature Genetics 24: 18-19, 2000 . 